community level, a community comprising 75,000 people. It used both professional and lay workers. Camps for instruction and voluntary sterilization were already operating and were to be expanded. By early 1966 some States had not even accepted the scheme in principle, though in the meantime the population had increased by at least another 25 million.

Deeds are now even more necessary than words and everyone will welcome India's recent removal of restrictions on the import of oral contraceptive pills. The United Nations Mission states that their disadvantage is "that an effective distribution system is imperative ... and the cost is high," but those objections would not seem to be insuperable. When the plans for district and rural community centres operate, as they must before any technique will succeed, the distribution problem should be largely solved. The formidable barrier of cost should not prove impassable in view of the great need to reduce the birth rate. In the meantime the intrauterine loop and sterilization are favoured by both the Government and the Mission, but the logistics of loop insertions on the necessary scale present a staggering problem. The Mission refers to more than 200,000 loops being inserted in Korea in a year and a half, but when Egypt started her planning programme 100,000 couples were using oral contraceptives by the end of one month. Desperate situations demand courageous remedies, and it may well be that India cannot afford not to use both oral contraception and the loop.

\section{Facial Pain and Depression}

Management of patients with chronic severe pain in the face or scalp is always difficult, the more so if no physical cause can be found. Atypical facial pain, or atypical facial neuralgia as it used to be called, is characterized by an aching, burning, nagging pain which patients feel in the deep structures of the face or scalp and find difficult to describe. The pain is poorly localized and does not conform to the anatomical boundaries of sensory nerve supply. The areas affected may be one or more of those supplied by the fifth or ninth cranial nerves, or the second and third cervical nerves. ${ }^{1}$ In certain cases the pain is bilateral. ${ }^{2}$ Usually it is constant, but though exacerbations lasting for hours or days may occur the patient is never free from pain.

The syndrome was first described as a clinical entity separate from trigeminal neuralgia in 1924 by C. H. Frazier and E. C. Russell, ${ }^{3}$ and later fully described by M. A. Glaser. ${ }^{4}$ In trigeminal neuralgia the pain is lancinating, short, knifelike, and of great intensity. It is felt superficially and occurs in attacks of sudden onset and short duration and is often precipitated by stimulation of the trigger zones and followed by periods of freedom. It always affects the well-defined distribution of the trigeminal nerve, and there are no abnormal physical signs. The incidence is equal in the sexes, whereas atypical facial pain is more common in women. ${ }^{1257}$ Atypical facial pain must also be distinguished from post-herpetic neuralgia, which may affect one or more divisions of the trigeminal nerve. It is characterized by the presence of small paper-white scars, which are anaesthetic though the surrounding rim may be hyperaesthetic. The pain is chronic, persistent, and often very severe. In migrainous neuralgia episodes of pain are felt in the trigeminal distribution and gradually build up in intensity over hours ; several attacks occur spaced closely together, followed by periods of freedom. The first division of the fifth nerve is usually affected, attacks occur commonly at night and may be associated with redness of one eye and discharge from or blocking of one nostril. Pain in the face may also be caused by disease of the teeth, sinuses, ears, nose, or throat ; it may be associated with arthritis of the temporomandibular joint (Costen's syndrome) or with cervical spondylosis ; or it may be due to giant cell arteritis.

The aetiology of atypical facial pain is not known, though a variety of causes have been suggested, including allergy, vasomotor dysfunction, disorders of the sphenopalatine ganglion, and conversion hysteria. ${ }^{6} \quad$ S. Lesse $^{7}$ described $_{18}$ cases of facial pain associated with depression, in 12 of which the patients gave a history of previous minor dental treatment or facial trauma. K. O. von Hagen ${ }^{8}$ treated patients suffering from chronic pain in various sites with electric convulsion therapy (E.C.T.) and found marked benefit from pain in all eight patients. He suggested that E.C.T. may have produced this effect by relieving depression. H. E. Webb and R. G. Lascelles $^{9}$ examined 31 patients with pain in the face and head of organic and non-organic origin and found that they were depressed and that many had markedly obsessional personalities. Treatment with antidepressant drugs resulted in alleviation of the depression in 25 patients, and much relief from pain. J. J. Bradley, ${ }^{10}$ also reporting on patients from St. Thomas's Hospital, found that if pain without organic cause came first and was followed by depression antidepressant treatment removed the depression and increased the tolerance of pain. If pain and depression began simultaneously, both were relieved by treatment of depression. R. G. Lascelles ${ }^{1}$ has recently found that in 53 patients with atypical facial pain and depression treatment with antidepressant drugs resulted in complete loss of pain in 29 patients and 10 were markedly improved. He carried out a controlled double blind trial on a further group of 40 patients. Those who had received phenelzine were significantly improved in both facial pain and depression compared with those receiving placebo. He stressed the danger of surgical intervention in this syndrome.

Chronic pain of organic origin may result in depression, and treatment of the depressive illness will not only remove or improve the depression but also help the pain. Atypical facial pain or localized pain without organic cause occurring elsewhere in the body with the same characteristics ${ }^{10}$ may be a symptom of an underlying depressive illness. The depressive illness may have the features of endogenous depression, ${ }^{10}$ with lowering of mood and diurnal variation, early morning waking, loss of weight, retardation, agitation, or feelings of guilt ; or more commonly be "atypical." In this type of illness described by E. D. West and P. J. Dally ${ }^{11}$ and W. Sargant ${ }^{12}$ the patients often described fatigue as a prominent symptom rather than depression. The patients have numerous somatic complaints, they feel irritable and are usually worse in the

Lascelles, R. G., Brit. F. Psychiat., 1966, 112, 651

2 Glaser, M. A., and Beerman, H. M., Arch. intern. Med., 1938, 61, 172.

3 Frazier, C. H., and Russell, E. C., Arch. Neurol. Psychiat. (Chic.), 1924, 11, 557 .

- Glaser, M. A., ibid., 1928, 20, 537.

5 McElin, T. W., and Horton, D. T., Ann. intern. Med., 1947, 27, 749.

Engel, G. L., ₹. occup. Med., 1961, 3, 249.

Lesse, S., f. nerv. ment. Dis., 1956, 124, 346.

Von Hagen, K. O., f. Amer. med. Ass., 1957, 165, 773.

- Webb, H. E., and Lascelles, R. G., Lancet, 1962, 1, 355.

Bradley, J. J., Brit. J. Psychiat., 1963, 109, 741.

1 West, E. D., and Dally, P. J., Brit. med. F., 1959, 1, 1491.

Sargant, W., Psychosomatics, 1960, 1, 14

and Siater, E., An Introduction to Physical Methods of Treatment in Psychiatry, 3rd ed., 1954. London. 
evening and have difficulty in going off to sleep. Phobic anxiety is not uncommon. Often patients have good previous personalities and frequently respond well to monoamine oxidase inhibitors. In this type of illness treatment should be with phenelzine and chlordiazepoxide hydrochloride. If endogenous depression is present imipramine or amitriptyline should be used. In cases of severe depression, or after failure of antidepressant drugs alone, E.C.T. may be required. If the patient is completely obsessed by pain and his life is a misery and other forms of treatment have failed, modified prefrontal leucotomy may be considered. The operation will not affect the pain, but will make the patient less preoccupied with it so that he can live a more normal life. ${ }^{13}$

When patients present with chronic pain, if no organic cause is found or even if there is an obvious organic cause such as post-herpetic neuralgia, a careful search should be made for symptoms of an associated depressive illness. If this is recognized and treated much unnecessary suffering will be prevented.

\section{Doctors in the Forces}

When the White Paper $^{1}$ on the period of severe restraint was published on 22 November we drew attention ${ }^{2}$ to its possible effects on doctors outside the N.H.S. On 15 December the clinical teachers were told they must wait until July 1967 for their rises "linked" to the seventh report of the Review Body, published in April 1966. Doctors in the armed Forces have now been told ${ }^{3}$ that they too must wait until July for their rises in pay, which will be back-dated to October 1966: and they have been told that the rise will be $10 \%$ only.

In the early 1960s recruitment of doctors into the armed Forces was very poor, and morale among Service doctors was low. After discussions between the B.M.A. and the Government a " new deal" was introduced for Service doctors. This was based on an acceptance by the Government of the B.M.A.'s advice " that to attract newly qualified young doctors in adequate numbers and of good quality they must be offered a substantial lead over the remuneration which they could expect as doctors in civilian life." A married general-duties medical officer over the age of 26 was offered a salary some $16 \%$ higher than the average earnings of an N.H.S. general practitioner. In the next year there was a dramatic improvement in recruitment of doctors. ${ }^{5}$

In 1963 the Review Body awarded general practitioners a rise which more or less abolished the Service doctors' lead; but in 1964 the latter were awarded increases of about $14 \%$, which restored the differential.

Service personnel other than doctors were given rises of about $18 \%$ in the biennial review of armed Forces' pay ${ }^{6}$ in April 1966. Service medical and dental officers were excluded from this review on the grounds that " since 1962 the pay of Service medical officers has taken account of increases awarded to civilian doctors," but the review made it clear that doctors would get a rise, retrospective to April, based on the next Review Body report.

So after publication of the report in May 1966 a new claim was made on behalf of Service doctors, who since their last

- Prices and Incomes Standstill : Period of Severe Restraint. Cmnd. 3150, 1966, H.M.S.O.

- Brit. med. \%., 1966, 2, 1341.

- Brit. med., 1966, 2, 1661.

- Ibid., $1962,1,1191$.

- Ibid., Suppl., 1963, 1, 247.

- Armed Forces Pay. Cmnd. 2881, 1966, H.M.S.O. rise in 1964 had seen their general-practitioner colleagues awarded $9 \%$ from the Review Body in 1965 and 30-35\% in 1966. The new claim was based on a restoration of the differential to the 1962 level, and, as the award to general practitioners had been phased, asked for $20 \%$ at once and the rest one year later. On 20 December the Minister of Defence, Mr. Healey, announced the terms of the award$10 \%$.

Many of the young men who joined the Services after 1962 signed on for a period of up to 16 years, in the firm belief that their pay would be related to that of general practitioners. Their faith is now shown to have been misplaced, and not surprisingly they are angry and disillusioned. They feel trapped, for unlike their colleagues in civilian practice Service doctors cannot easily resign and emigrate or form protest groups. This is yet another example of the shabby treatment given by the Government to a small group with inadequate means of protest. How can doctors believe the promises of a Government which so often goes back on its pledged undertakings?

\section{Fatigue Fracture in the Femur}

Stress, fatigue, or march fractures in the shaft of the second metatarsal are common enough to be familiar to most surgeons and to be readily diagnosed on clinical evidence before $x$-ray changes occur. Similar fatigue lesions have been described at many other sites, the next most common being the shaft of the tibia and the upper and lower ends of the fibula. The condition is not confined to man, M. B. Devas ${ }^{1}$ having reported its occurrence in the navicular of the greyhound. The pathological changes may well be analogous to those of fatigue failure of metal, in which repeated stress short of that required to produce acute fracture causes a change in crystalline structure which leads to ultimate failure. In bone repair proceeds pari passu with weakening, so complete failure is less common than in metal. In fatigue fractures the bone is otherwise normal, and this is the important distinction between these and pathological fractures.

A fatigue fracture in the neck of the femur was first recorded by $\mathrm{A}$. Blecher ${ }^{2}$ in 1905, and small numbers of cases were reported from time to time until 1964, when J. Ernst ${ }^{3}$ described 13 cases in Danish Army conscripts. In 1965 Devas $^{4}$ reported 32 fractures in 25 patients, and recently L. D. Blickenstaff and J. M. Morris ${ }^{5}$ have recorded 41 fractures in 36 patients, again military recruits. Though the patients in these series were young, many were left with some residual disability, and clearly this fracture should be borne in mind by doctors who look after groups of patients who may be at risk.

The sort of person most likely to sustain a fatigue fracture of the femur, and in whom the early stages are most likely to be missed, is a young man, otherwise healthy, who has recently undergone a period of prolonged and unaccustomed physical activity. Military recruits have accounted for most of the reported cases, but the condition is just as likely to occur in athletes at the beginning of the season or in middleaged men filled with sudden enthusiasm for strenuous outdoor

\footnotetext{
Devas, M. B., f. Bone ft Surg., 1961, 43B, 540.

Blecher, A., Med. Klin., 1905, 1, 305.

3 Ernst, J., F. Trauma, 1964, 4, 71

4 Devas, M. B., 7. Bone ft Surg., 1965, 47B, 728.

s Blickenstaff, L. D., and Morris, J. M., ibid., 1966, 48A, 1031.
} 